\title{
A Novel Method of Case Teaching
}

\author{
Hu Yamin ${ }^{1}$ \\ ${ }^{1}$ Air Force Early Warning Academy, Wuhan 430019, \\ China \\ Lv Shujun ${ }^{1}$ \\ ${ }^{1}$ Air Force Early Warning Academy, Wuhan 430019,
}

China

\author{
Fang Qiqing $^{1}$ \\ ${ }^{1}$ Air Force Early Warning Academy, Wuhan 430019, \\ China \\ Zhang Wei ${ }^{1}$ \\ ${ }^{1}$ Air Force Early Warning Academy, Wuhan 430019,
}

\author{
Xiao Lei ${ }^{1}$ \\ ${ }^{1}$ Air Force Early Warning Academy, Wuhan 430019, China
}

\begin{abstract}
Based on the case teaching implementation process as background, we propose three suggestions with changing teaching idea, transforming teaching method and improving professional ability. And we also put forward to carry out three implementations with good preparation before class, the class discussion and summary after class for students .
\end{abstract}

Keywords: case teaching; teacher; student.

\section{INTRODUCTION}

Case teaching is a teaching method based on the requirement of teaching subjects, teaching objectives and teaching cases to improve the students' ability to solve practical problems.

The cases in the case teaching are mostly real events in life. The emphasis of the case teaching should be at the contradiction of realistic problems as a starting point, stimulate students to take the initiative to find problems, analyze and solve problems, which are also the authenticity and concreteness of case teaching.

In the process of case teaching, the teaching subject is the student instead of the teacher. The teaching cognitive process is no longer through multiple students listen to a teacher, for teaching and acquisition of knowledge, but rather by analyzing the contradiction, trying to solve these specific problems. That is to say, student-centered teaching model is the main idea of case teaching.

\section{Three changes in teachers}

\subsection{Changing teaching ideas}

In traditional teaching, the teacher's permanent dominant position leads to a serious consequences including passive to accept knowledge for students, active learning new knowledge, unable to solve the problems, etc. However, in the case teaching, student-centered teaching model is the implementation of the case teaching process of students under teacher's guidance to the process of case analysis. This requires teachers to change teaching idea in teaching, attaches great importance to the students' subject position in the process of teaching, encourages students to actively joining the learning.

\subsection{Changing the traditional teaching methods}

Case teaching requires teachers to break the traditional force-feeding teaching methods. Teachers should attach more attention to strengthen the students take the initiative to find the problem, the ability to solve the problem. Case teaching can make teachers from depression formed by the traditional teaching method of teaching atmosphere, using case analysis of flexible, greatly to mobilize students' learning interest and enthusiasm, improve students to find problems, the ability to analyze and solve problems, promote students theory and practice of cohesion, so as to really improve the efficiency of classroom teaching, for the realization of the training objective of applied talents to lay the good foundation.

\subsection{Improving teachers' professional ability}

It is important for the case teaching smooth implementation to improve teachers' professional ability. Case teaching requires teachers have various ability. Specifically, the teacher must have a good case selection and analysis ability, can select from the ramifications of the case of the most representative and typical teaching case, and detailed analysis was carried out on the case; Good classroom management and organization ability, teaching monitoring ability, can according to the case discussion guides the student to a system, properly organize classroom teaching, and timely feedback and adjust to the effect of classroom teaching; Good ability of generalization and 
summary to the results of case analysis and discussion to accurately summarized and refined, so as to help students achieve the sublimation of analysis to the system theory knowledge from practice.

\section{Three implementations in students}

\subsection{Implementation of good preparation before class}

From the point of view, it must be taught in the early stage of the teacher, on the basis of self-study preparation before class. Therefore, 1 to 2 weeks before implementing case teaching, must send material to each student, ask them to read and think, according to the topic assigned by the teacher read the case, the necessary analysis and calculation, to seek the answer of the case, to prepare for class discussion, to make the students learn to autonomous learning, reading, understanding, and calculating and other basic skills and comprehensive knowledge, analysis, problem solving skills. Case only full preparations before class, class debate will be enthusiastic, lively atmosphere.

\subsection{Implementation of the class discussion}

Class discussion belongs to a wide range of cooperative learning, in the role of case teaching, at the same time in the organizational difficulty is very big also. Often occurs in the process of organization, students do not actively participate in the discussion, problems such as insufficient class discussion. In order to implement the class discussion, students can according to the basic idea of this discussion: one is mainly about the case is what problem? Case teaching provide the case often is not a whole set of system of knowledge, the problem may be more than one, and these problems have advocate have second, is like concealed, its information tend to be chaotic, which requires students to recognize, pursuit, to grasp the key facts, its excellent so as to cultivate their ability to find problems. The second is the problem what reflects the theory? Purpose is to cultivate students to promote the understanding of the specific things to the theory of abstract ability, namely be situated, shallow to deep. Three is how to solve this problem? Purpose is to cultivate students' ability to apply theory to solve practical problems. Discussion should be carried out in accordance with the previously scheduled program, each speech scouring orderly, reasonable time, discussion, when a person to speak, others usually don't get in a word, not to be involved in other things scattered themes.

\subsection{Implementation of good papers after class}

After class discussion, students will reflect the key, difficult and hot issue in the case first position, combined with their own professional and future writing essay, by training their ability of writing power of expression and practical application. One is to choose the right topic. Close to the professional, close to the troops, close to the post, from collecting cases in the practical work, from exploring research problems in the practical work. 2 it is to adhere to the combination of theory and practice, use knowledge to explain various normal and abnormal phenomena encountered in the actual work, combining with their own practice experience, the theoretical sublimation, extracting accord with the actual situation, promote the significance of work better operating methods, steps and experience. By deep research to the practice, and eventually will be used to guide the practice of knowledge, to solve the problems encountered in practice.

\section{Conclusions}

In this paper, we propose a novel teaching idea including changing teaching idea, transforming teaching method and improving professional ability. And we will endeavor in improving our teaching level in case teaching.

\section{Acknowledgements}

Sponsored by Fellowship for: 2013ZDJC0101

\section{References}

[1] Wang wei, etc. Some thoughts on implementing case teaching. Journal of shijiazhuang vocational technology institute, 2013 (8)

[2] Wang Chengxue, etc. The application of case teaching in military academy education study. Journal of continuing education, 2014 (2)

[3] Li La. Case teaching: to promote vocational colleges of teacher professional development effective way. Journal of contemporary vocational education, 2011 (1)

[4] Sun Xiaoping. Case teaching new agent. Journal of wuxi vocational and technical college, 2010 (2)

[5] Chen Qiong. Innovative teaching methods to promote the case type teaching. Journal of CPC guizhou provincial party committee party school, 2009 (5)

[6] $\mathrm{Hu}$ Minghui. Case type teaching mode in higher vocational colleges analysis. Journal of wuhu vocational technical college, 2011 (1) 